\title{
Radiographic Comparison of Vertical Skeletal and Dental Parameters in Skeletal Open Bite
}

\author{
Mártha Krisztina Ildiko*, Pálffy Balázs Ákos, Panaite Irinel \\ Faculty of Dental Medicine, University of Medicine and Pharmacy Tirgu Mures, România
}

Objective: The purpose of our randomized study was to compare the skeletal and dental values in open bite cases using lateral cephalometric analysis and panoramic X-rays analysis and to evaluate if PR is a reliable diagnostic method in skeletal malocclusions. Methods: 21 (6 boys, 15 girls) patient with skeletal open bite were selected and both radiological examinations were performed. "Modified cephalometric analysis" on panoramic X-rays and Steiner's cephalometric analysis was performed using AudaxCeph software. Statistical analysis was performed using the Pearson correlation method and SPSS statistical software for comparison. Results: Skeletal values like anterior facial height $(\mathrm{AFH})$, angles between Frankfort horizontal and mandibular/palatal plane (ML/H and $\mathrm{NL} / \mathrm{H})$ showed no statistical significance, mandibular plane/ramus tangent angle (goniac angle) and mandibular plane/palatal plane angle (ML/RL, ML/NL) showed high or moderate (posterior facial height - PFH) significant statistical interrelation $(r=0.46-0.80)$. Almost all dental parameters were statistically significant, from moderate to high ( $r=0.56-0.79$ ). The only statistically insignificant dental parameter was the mesial cusp tip of the upper first molar/palatal plane (ms-NL) distance $(r=0.32)$. Vertical skeletal and dental parameters on panoramic X-rays can moderately approximate lateral cephalomteric values. This means that mostly in skeletal malocclusions, panoramic X-rays cannot be used for quantitative determination of the parameters.

Keywords: skeletal open bite, cephalometric analysis, panoramic X-rays

Received: 28 January 2016 / Accepted: 04 July 2016

\section{Introduction}

The relationship between the cranial base, facial and dentalarch morphology is mostly of anthropologist concerne, especially in studies of racial differences. Studies on dried skulls revealed certain modifications of the angulation of the skull base determined by racial variations [1], furthermore a relationship was found between these variations and different types of malocclusions [2]. Conclusions of Björk's follow-up X-ray study on 243 swedish individuals showed that in coordination with the rotation of the cranial base and the brain case, there is also a rotation of the facial structures and so there is a correlation between the morphology of the skull base and the position of the maxilla and mandible to each other and both to the skull base [3]. Regarding the development and growth of the skull it was found that individual segments of the cranial base follow either the neural or the general skeletal pattern of growth, but not an intermediate one [4].

One of the most important part of the cranial base is the sella turcica. It is located in the middle cranial fossa, lies on the intercranial surface of the body of the sphenoid, consists of a central pituitary fossa, bounded anteriorly by the tuberculum sellae and posteriorly by the dorsum sellae. Two anterior and two posterior clinoid processes project above the clinoid fossa, these can fusion, forming the sella turcica bridge.

The anatomy of the sellae is variable and has been classified in five types: round, oval,flat, shallow and J-shaped. The size of the sellae is also variable, the antero-posterior

* Correspondence to: Krisztina lldiko Mártha

E-mail: marthakriszti@yahoo.com diameter varies from five to $16 \mathrm{~mm}$, the vertical depth from four to $16 \mathrm{~mm}$ [4].

The relationship between malocclusions and skeletal morphology is a popular topic of maxillofacial developmental research. As one of the most common diagnostic records is the cephalogram, the relationship among cranial base, maxilla and mandible can be easily determined. Using Steiner's cephalometric analysis, malocclusions can be easily classified by ANB angle. Facial type or vertical diagnosis can be performed by measuring the Down's MP (mandibular plane) angle [5].

Tha sagital length of the maxilla is represented by the distance between the most anterior (SpNA) and the most posterior (SpNP) bony point of it. Mandibular basal length can be measured between two cephalometric points: gnathion $(\mathrm{Gn})$ and gonion $(\mathrm{Go})$. The distance between the middle of the sellae turcica(S) and the nasofrontal suture $(\mathrm{N})$ represent the length of the anterior cranial base.

The aim of this study was to compare the cranial base length, the sellae turcica morphology and dimension and the maxilla and mandible length is different types of malocclusions.

\section{Material and methods}

Pretreatment lateral cephalometric radiographs were randomly chosen from 136 Romanian subjects, who were referred for orthodontic treatment to the Orthodontic Department of University of Medicine and Pharmacy Tirgu Mures. Subjects mean age was $12.3 \pm 3.8,60.2 \%$ were female, $39.8 \%$ were male subjects. All subjects were clinically healthy, with no syndromes, clefts or other malformations. 
Only good quality radiographs were used and malocclusion type was not criteria for sample selection.

All lateral cephalograms were taken with the same X-ray machine by trained radiographer. Manual interpretation of all cephalograms were performed by two orthodontists, experienced clinicians familiar with lateral cephalometric radiographs interpretation. Cephalograms were numbered, so at the time of the analysis the observers could not identify the patient. Mean values of the two determinations were calculated for each measurement. (Table I).

Anterior cranial length (S-N), maxillary length (SpNA$\mathrm{SpNP})$, mandibular base length (Gn-Go) were measured. Using the ANB (Steiner cephalometric analysis) and MP angles (Downs cephalometric analysis) skeletal sagital and facial type diagnosis was performed [5]. The diameter of the sellae turcica was determined using a professional ruler. The diameter was measured as the largest antero-posterior dimension, parallel with the Frankfort horizontal. The data was stored and processed in the statistical Microsoft Excel table. Statistical significance was performed using GraphPad InStat program.

Table I. Definition of reference points and lines used in the panoramic radiographs (PR) and cephalometric analysis (LCR)

\begin{tabular}{|c|c|}
\hline Variable & Definition \\
\hline S & midpoint of Sellae Turcica \\
\hline $\mathrm{N}$ & anterior limit of naso-frontal suture \\
\hline A & anterior limit of the apical base of the maxilla \\
\hline B & anterior limit of the apical base of the mandible \\
\hline Gn & $\begin{array}{l}\text { most inferior point of the lower contour of the bony } \\
\text { chin }\end{array}$ \\
\hline Go & gonial tangent point \\
\hline $\mathrm{Pg}$ & most anterior point of the contour of the bony chin \\
\hline $\mathrm{Ba}$ & $\begin{array}{l}\text { lowest point on the anterior rim of the foramen mag- } \\
\text { num }\end{array}$ \\
\hline Ptm & apex of the pterygomaxillary fissure \\
\hline Po & the outermost and most superior point of the ear rod \\
\hline Or & the lowest point of the infraorbital rim of the orbit \\
\hline $\mathrm{SpNa}$ & anterior tip of the nasal spine \\
\hline SpNP & the most posterior aspect of the palatine bone \\
\hline $\mathrm{N}-\mathrm{S}$ & anterior cranial base \\
\hline OcP & $\begin{array}{l}\text { occlusal plane (drawn through the region of the over- } \\
\text { lapping cusps of the first premolars and first molars) }\end{array}$ \\
\hline $\mathrm{AFH}$ & anterior facial height \\
\hline $\mathrm{PFH}$ & posterior facial height \\
\hline ML (Go-Gn) & mandibular plane \\
\hline NL (SpNA-SpNP) & palatal plane \\
\hline $\mathrm{RL}$ & $\begin{array}{l}\text { ramus tangent (tangent to the posterior border of the } \\
\text { ramus through the most posterior point of the condyle) }\end{array}$ \\
\hline $\mathrm{H}$ (Co-Or) & $\begin{array}{l}\text { modified Frankfort horizontal (Or- the most superior } \\
\text { point of the condyle) }\end{array}$ \\
\hline is & $\begin{array}{l}\text { incisal tip of the most protruded maxillary central } \\
\text { incisor }\end{array}$ \\
\hline isa & $\begin{array}{l}\text { root apex of the most protruded maxillary central } \\
\text { incisor }\end{array}$ \\
\hline ii & $\begin{array}{l}\text { incisal tip of the most protruded mandibular central } \\
\text { incisor }\end{array}$ \\
\hline iia & $\begin{array}{l}\text { root apex of the most protruded mandibular central } \\
\text { incisor }\end{array}$ \\
\hline $\mathrm{ms}$ & mesial cusp tip of the upper first molar \\
\hline msa & mesial root apex of the upper first molar \\
\hline $\mathrm{mi}$ & mesial cusp tip of the lower first molar \\
\hline mia & mesial root apex of the lower first molar \\
\hline
\end{tabular}

\section{Results}

Thirt-four percent of the subjects showed class I., 59\% class II. and 7\% class III. skeletal malocclusion. Analysing the skeletal disorder by subjects gender, we found the following percentages: female subjects $20.5 \%$ (male 13.2\%) class I., $33.8 \%$ (males 25\%) class II. , 5.8\% (males 1.4\%) class III. The statistical significancy was $\mathrm{p}=0.0690$.

Vertical skeletal diagnostics was performed by MP angle and we found the following distribution: $30.8 \%$ hiperdivergent, $51.47 \%$ normodivergent and $17.64 \%$ hipodivergent. 40 subjects were normodivergent-class II., 28 subject were diagnosed as hiperdivergent -class II. From class I. subjects most were normodivergent as well. We found no ststistical significancy, as $\mathrm{p}=0.600$. (Table II.)

Statistically significant differences among linear skeletal parameters and sellae diameter were found in class I. malocclusion $(\mathrm{p}=0.013)$. $58.87 \%$ of the subjects presented round shaped sellae (62.5\% were skeletal class II.), $23.52 \%$ oval shape ( $40 \%$ of them presented class I. malocclusion), in $16.17 \%$ shallow shape and in $1.44 \%$ of the cases the shape of the sellae was flat. Statistical analysis presented no significancy $(p=0.729)$ regarding sellae's shape in different types of malocclusion, althought skeletal class II. cases presented the most anarchic sellae shapes.

Comparing linear measurements of skeletal length and sellae diameter, we found that the smallest diameter of the sellae appears in class III. malocclusions, where other skelatal length present the lowest mean values also.

\section{Discussions}

Orthodontic treatment need is presenting an increased tendency nowadays. Population-based studies revealed that malocclusions occurred primarily in girls [6]. Cross-sectional studies showed that the prevalence of malocclusion traits did not change with class I. being more prevalent in all the age groups and gender followed by class II. and class III. Females were observed to have more class I. than males [7]. Some epidemiological surveys concluded that boys present a higher number of class II and class III malocclusion $[8,9]$. Even thought no statistical significancy was obtained regarding class I. and class II. malocclusions, our data showed a slightly increased percentage of class II. malocclusions in both genders.

Analysing the corelation of the facial type and malocclusion, we found that the most frecvent facial morphology described a normodivergent facial architecture in class I. and class II. malocclusions. The same results were found in several epidemiologic studies $[10,11]$ but most of them revealed, that vertical and sagital skeletal growth and development is strongly influenced by rase and function.

An average dimension of the sellae is difficult to predict, although significant differences were found between the older (15 years or more) and the younger (11-14 years) age groups regarding length, depth, and diameter. When skeletal type was compared with sella size, a significant difference was found in the diameter of sella between the 
Table II. Mean values, standard deviation (SD) and correlation coefficients for PR and LCR parameters (SD= standard deviation, mean value $(d)=$ difference between LCR and PR mean values, $r=$ Pearson's correlation coefficient, ${ }^{*} p<0.05$, ${ }^{* *} p<0.01$, n.s. - statistically not significant)

\begin{tabular}{|c|c|c|c|c|c|c|c|}
\hline \multirow[b]{2}{*}{ Parameters } & \multicolumn{2}{|c|}{ LCR } & \multicolumn{2}{|c|}{ PR } & \multicolumn{2}{|c|}{ LCR-PR } & \multirow{2}{*}{$\begin{array}{c}\text { Correlation coefficient } \\
r\end{array}$} \\
\hline & Mean value & SD & Mean value & SD & Mean value $(\mathrm{d})$ & SD & \\
\hline \multicolumn{8}{|c|}{ Skeletal parameters } \\
\hline $\mathrm{AFH}(\mathrm{mm})$ & 79.7 & 6.7 & 93.1 & 17.1 & -13.4 & 15.9 & 0.36 n.s \\
\hline $\mathrm{PFH}(\mathrm{mm})$ & 50.9 & 5.1 & 59.2 & 11.8 & -8.3 & 10.5 & 0.46 * \\
\hline $\mathrm{ML} / \mathrm{RL}\left({ }^{\circ}\right)$ & 124.6 & 4.5 & 125.5 & 5.9 & -0.9 & 3.5 & $0.80^{* \star}$ \\
\hline $\mathrm{ML} / \mathrm{H}\left({ }^{0}\right)$ & 24.7 & 4.3 & 27.6 & 5.1 & -2.9 & 5.1 & 0.41 n.s \\
\hline $\mathrm{NL} / \mathrm{H}\left({ }^{\circ}\right)$ & 2.6 & 2.1 & 8.1 & 5.2 & -5.5 & 6.1 & -0.32 n.s \\
\hline $\mathrm{ML} / \mathrm{NL}\left({ }^{0}\right)$ & 25.3 & 4.2 & 19.3 & 4.9 & +6 & 3.3 & $0.74^{\star \star}$ \\
\hline \multicolumn{8}{|c|}{ Dental parameters } \\
\hline is-NL (mm) & 26.5 & 3.1 & 29.8 & 4.7 & -3.3 & 3.3 & $0.70^{* *}$ \\
\hline isa-NL (mm) & 4.6 & 1.7 & 3.6 & 2.4 & +1 & 2.2 & $0.43^{*}$ \\
\hline ii-ML (mm) & 34.1 & 3.3 & 38.2 & 7.3 & -4.1 & 5.7 & $0.65^{\star *}$ \\
\hline iia-ML (mm) & 11.9 & 2.5 & 18.9 & 5.5 & -7 & 4.6 & 0.56 ** \\
\hline ms-NL (mm) & 20.3 & 3.7 & 25.4 & 4.2 & -5.1 & 4.7 & 0.32 n.s \\
\hline msa-NL (mm) & 4.9 & 2.7 & 5.4 & 2.8 & -0.5 & 2.7 & 0.51 * \\
\hline mi-ML (mm) & 25.5 & 2.8 & 31.2 & 6.3 & -5.7 & 4.4 & $0.79^{* *}$ \\
\hline mia-ML (mm) & 8.6 & 2.5 & 8.6 & 3.4 & 0.0 & 2 & $0.68^{* *}$ \\
\hline
\end{tabular}

Class II and Class III subjects [12,13]. One of the reason of variable dimension is that sellae turcica is housing the pituitary gland, and any abnormality or pathology in the gland could manifest from an altered shape of the sella turcica [14]. Radiological literature has been reported a range from 4 to $12 \mathrm{~mm}$ for the vertical and 5 to $16 \mathrm{~mm}$ for the antero-posterior dimension of the sellae $[4,15]$. Our measurements are in the above mentioned range as far as minimum and maximum values are concerened, although the mean values are almost the same for each type of malocclusion. In contrast with our findings, other studies could not find a significant association between facial types and the mean size of pituitary fossa $[16,17]$ and the depth and diameter of sella turcica in class I, class II, and class III patients were relatively the same [18].

In contrast with our results, other studies found normal morphology in of pituitary fossa [19], dysmorphologic types were more common in diabetic patients [20]. Bridging and calcification of intracranial ligaments were found in various dental anomalies, this was considered highly suggestive of a genetic etiology underlying both these conditions. palatally displaced canine and second mandibular premolar aplasia and dental transposition were conditions when bridging was found [21,22]. The average shape of sella turcica is considered to be common among all the groups of different skeletal pattern and no significant difference in mean sella turcica length, width and height was found between the groups.

\section{Conclusions}

The orthodontist should be familiar with different morphologies of the sella turcica to differentiate normal from abnormal appearance. Most (58.87\%) of the subjects presented round shaped sellae and skeletal class II. cases presented the most anarchic sellae shapes. Statistically significant diffences among linear skeletal parameters and sellae diameter were found in class I. malocclusion $(\mathrm{p}=0.013)$. Comparing linear measurements of skeletal length and sellae diameter, we found that the smallest diameter of the sellae appears in class III. malocclusions, where other skelatal length present the lowest mean values also.

\section{Conflicts of interest}

The authors report no conflicts of interest.

\section{Acknowledgements}

This paper was published under the frame of Internal Competition of Research Grants, grant number 35/11.12.2013 of University of Medicine and Pharmacy, Tirgu Mures, Romania.

\section{References}

1. Huxley TH. On two widely contrasted forms of the human cranium. J Anat Physiol. 1867;11:60-77.

2. Coben E. The spheno-occipital synchondrosis: The missing link between the profession's concept of craniofacial growth and orthodontic treatment. Am J Orthod Dentofacial Orthop. 1998;114(6):709-712.

3. Björk A. Prediction of mandibular growth rotation. Am J Orthod Dentofacial Orthop. 1969;55(6):585-599.

4. Moffitt $\mathrm{AH}$. Discovery of pathologies by orthodontists on lateral cephalograms. Angle Orthod. 2011;81(1):58-63. doi: 10.2319/040510190.1.

5. Jacobson A, Jacobson RL. Radiographic Cephalometry: From Basics to 3-D Imaging. Quintessence Pub. 2006:63-78.

6. KomazakiY, FujiwaraT, Ogawa T, et al. Prevalenceand gender comparison of malocclusion among Japanese adolescents: A population-based study. Journal of the World Federation of Orthodontists. 2012;e67-e72.

7. Aslam K, Nadim R, Rizwam S. Prevalence of Angle's malocclusion according to age groups and gender. Pakistan Oral \& Dental Journal. 2014;34(2):362-365.

8. Tang EL, Wei SH. Recording and measuring malocclusion: A review of the literature. Am J Orthod Dentofacial Orthop. 1993;103:344-351.

9. Komazaki Y, Fujiwara $\mathrm{T}$, Ogawa $\mathrm{T}$, et al. Association between malocclusion and headache among 12- to 15-year-old adolescents: a population-based study. Community dentistry and oral epidemiology. 2014;42(6):572-580.

10. Porntip P. Siriwat, Jarabak JR. Malocclusion and Facial Morphology Is there a Relationship?. Angle Orthod. 1985;55(2):127-138.

11. Saltaji H, Flores-Mir C, Major PW, Youssef M. The relationship between vertical facial morphology and overjet in untreated Class ॥ 
subjects. Angle Orthod. 2012;82(3):432-440.

12. Alkofide EA. The shape and size of the sella turcica in skeletal Class I, Class II, and Class III Saudi subjects. Eur J Orthod. 2007;29(5):457-463.

13. Andredaki M, Koumantanou A, Dorotheou D, Halazonetis DJ. A cephalometric morphometric study of the sella turcica. Eur $\mathrm{J}$ Orthod. 2007;29(5):449-456

14. Pisaneschi M, Kapoor G. Imaging of the sella and parasellar region. Neuroimaging Clinics of North America. 2005;15:203-219.

15. Jones RM, Fagir A, Millett DT, Moos KF, McHugh S. Bridging and dimensions of sella turcica in subjects treated by surgical-orthodontic means or orthodontics only. Angle Orthod. 2005;75:714-718.

16. Mahmood Shah A, Bashir U, Tasleem I. The shape and size of the sella turcica in skeletal class I, II \& III in patients presenting at Islamic International Dental Hospital, Islamabad. Pakistan Oral and Dental Journal. 2011;31(1):104-110.

17. Preston CB. Pituitary fossa size and facial type. Am J
Orthod. 1979;75(3):259-263.

18. Valizadeh S, Shahbeig S, Mohseni S, Azimi F, Bakhshandeh $\mathrm{H}$. Correlation of Shape and Size of Sella Turcica With the Type of Facial Skeletal Class in an Iranian Group. Iranian J Radiol. 2015;12(3):e16059. doi: 10.5455/2320-6012.jijms20140529

19. Chauhan P, Kalra S, Mongia SM, Ali S, Anurag A. Morphometric analysis of sella turcica in North Indian population: a radiological study. Int $\mathrm{J}$ Res Med Sci. 2014;2(2):521-526. doi: 10.5455/2320-6012.jirms20140529.

20. Bavbek NC, Dincer M. Dimensions and morphologic variations of sella turcica in type 1 diabetic patients. Am J Orthod. 2014;145(2):179-187. doi: 10.1016/j.ajodo.2013.10.011.

21. Leonardi R, Barbato E, Vichi M, Caltabiano M. A sella turcica bridge in subjects with dental anomalies. Eur J Orthod. 2006;28:580-585.

22. Leonardi R, Farella M, Cobourne MT. An association between sella turcica bridging and dental transposition. Eur J Orthod. 2011;33:461465. DOI: http://dx.doi.org/10.1093/ejo/cjq106. 